\title{
Editorial
}

\section{Reflection, Analysis and Change: The Decade of Pain Control and Research and its Lessons for the Future of Pain Management}

Mark V. Boswell MD, PhD1, and James Giordano, PhD., M.Phil²

'The physician must be able to tell the antecedents, know the present, and foretell the future- must mediate these things, and have two special objects in view ... namely, to do good, or to do no harm'

Hippocrates (1)

\section{Introduction: The Antecedents}

As noted in this journal over the past year, pain medicine faces a crisis - literally a point of potential change (2-4) - brought to the fore, at least in part, by the efforts and outcomes of the Decade of Pain Control and Research (2000 - 2010). To be sure, this is more than a mere crisis in confidence, as a convergence of factors threatens the existence of pain management as a profession, and its authenticity as a practice. The complexity of pain- as symptom, disease and illness - may be one factor in the crisis. Despite our sophisticated research institutions, questions remain about the nature of pain, its effect upon - and the effects of - the brain, mind, consciousness and self of the pain patient, and what these contexts portend for the development and translation of diagnostic and therapeutic techniques, technologies and approaches (5). In short, we may need to re-examine "meanings" and "values" inherent to the experience and expression of pain, and equally examine such values in relation to the definition, and conduct of evidence-based pain medicine (6).

Indeed, technology provides invaluable tools for diagnoses and treatments. But, technology alone does not provide the diagnosis, heal the patient, or sustain the profession and practice of pain medicine (7-9). This remains within the humanitarian domain of "care," in the literal sense, here construed as concern, worry and regard. In this way, we argue that any regard for the pain patient - as the subject of the clinicians' moral responsibility - must address the nature of pain as physical and phenomenal experience, its meanings, the needs and vulnerabilities it incurs in each individual, and from this determine what and how existing and new technologies and techniques may be employed to serve the patient's best interests (10). In other words, the good of science in pain medicine is inextricably woven into its prudent use for the good of the pain patient.

From: ${ }^{1}$ Professor and Director, Pain Research and Treatment Program, Texas Tech University Health Sciences Center, Lubbock TX. ${ }^{2}$ Fellow, Centre for Philosophical Psychology, Blackfriars Hall, University of Oxford, Oxford,

UK. Director, Center for Neurotechnology Studies, Potomac Institute for Policy Studies, Arlington, VA. Visiting Professor of Neuroscience and

Ethics, Texas Tech University Health Sciences Center, Lubbock TX

Address correspondence:

Prof. J. Giordano, PhD Center for Neurotechnology Studies Potomac Institute for Policy Studies 901 N. Stuart St, Suite 200 Arlington, VA 22203 E-mail: jgiordano@potomacinstitute.org james.giordano@bfriars.ox.ac.uk

Disclaimer: This work was supported, in part, by grants from the Nour Foundation and Office of Naval Research Brain Injury Disorders Management Initiative; BIDMI (JG), an American Academy of Pain Medicine-Pfizer Visiting Professorship (JG), the $\mathrm{N}_{3} \mathrm{P}_{3}$ Project (JG), and funding from the Texas Tech University Health Sciences Center, Lubbock TX (MVB, JG).

Free full manuscript: www.painphysicianjournal.com 


\section{The Technologic Trend}

It is not so much that the practice of pain medicine has become overly dependent upon technology, but rather that other, extra-medical forces may sway (i.e. "pull") the use, if not misuse of technology away from the core imperative to use such devices and approaches as wholly for the patients' best medical interest(s). Inarguably, one of these "pulling forces" has been misaligned economic incentives that have commodifed translational applications of science and technology, and instantiated conditions of "medicinefor-profit"; more simply put, the misappropriation of scientific and technologic resources in accordance with a business or market ethos, rather than one of patient-centered beneficence $(11,12)$.

As a result, technology is increasingly viewed as an end, rather than a means by which to enable or enact the ends of what Pellegrino refers to as a "right and good healing" (13). Perhaps a bit of clarification is required here; first, it is important to note that good entails right. The good of pain care mandates that technology be used in ways that are methodologically "right" (i.e. appropriate and maximally effective) based upon the knowledge (regarding mechanism, action and effect) at hand. However, technical rectitude alone does not constitute "good"; to sustain beneficent use any and all techniques and technologies must be applied in those ways that maximize benefit(s) to the patient. To do otherwise would be to bastardize or refute the knowledge and capability conferred by science and technology in ways that are inconsistent with the core philosophical premises of medicine.

A number of factors make the specialty of pain medicine unique. Although relief of suffering appears as a central tenet of medicine, in practice it receives little attention, and the suffering of pain - particularly chronic pain, remains enigmatic $(14,15)$. Suffering is not readily quantified, and thus measurement remains problematic. Based upon this objective vagary, the treatment of pain remains equally difficult to accomplish, even given the most advanced technologic means. While Stanley Reiser has lauded the invention of the stethoscope as a turning point in the technologization of medicine (16), we should not forget that there is no "stethoscope with which to auscultate pain." Instead, the 'sounds of pain' are conferred through the subjective reports of the patient. Pain by its nature occupies the realm of first-person experience, and while certainly a symptom, is often "felt" and "known" more as illness than as disease. It is this subjective dimension that has rendered pain so difficult to both assess, and to treat.

\section{A Call for Complementarity}

For many reasons, the concept of pain as disease falls flat, and as such the disease-based, curative models of medicine can be ineffectual - if not at times wholly unsuitable - to address and "care" for the chronic pain patient (2). To be sure, pain is a bio-psychosocial event, experience, and expression. We posit that in light of this, pain medicine- as a specialty - must be equally bio-psychosocial in its orientation and approach. A uni-dimensional model will not work; rather, an approach that is foundationally complementary in its curative and healing capacity appears to be best aligned with current concepts of pain, and the predicament of pain patients (17). This "Asclepian-Hygieian" model would be built upon a maxim of "...cure when possible, heal as capable, and care always", and would axiomatically be inclusive, multi- (if not trans-) disciplinary, and integrative (18). This is not to imply that technology cannot nor should not be used in such a complementary approach. Quite the opposite; it may well be that technology offers assets that can be employed to better define the substrates and effects of pain as illness, and may be instrumental in enhancing the delivery of care. But if this is to be the case, it is not sufficient that this technology exists. Instead, it must be made available to the clinician as an implement of practice when and where appropriate (to the needs of a given patient), and must be accessible and affordable to those patients who require its benefits (7-9). On one hand this establishes the requirement(s) for health care reforms that empower physicians to utilize state-of-the-art diagnostics and therapeutics as necessary (re-iteratively, to fulfill the best interests of the patient). We have described how certain economic systems of resources allocation and distribution might best accommodate these goals (19).

On the other hand, the use of any technique or technology (regardless of whether new or old) requires that the pain physician act as steward of knowledge both to inform and guide patient insight, and shepherd the nature and direction of care. We argue that these constructs must act as a complementarity, else any system of technological advancement and infrastructural health care reform will likely remain unsuccessful. Admittedly, the stewardship and use of techniques and technologies in pain care in ways that are both right and good often becomes problematic. 
The admonition to do no harm to a patient who manifests a disorder that is difficult (if not impossible) to objectively measure poses profound challenges for the pain physician $(14,15)$.

This is particularly true for the physician who relies only upon technology, and has no grounding in the philosophy and ethics of medicine, or interest in pain medicine as a social good. This challenge is compounded by a lack of medical school education about pain, and training in pain management. The current norm is that instruction in pain care consists of little more than a postscript to the basic sciences. So while mechanisms of pain and analgesia are taught during basic neuroscience courses, there is no direct link to how the complexities of these systems are relevant to the challenges of clinical pain management.

\section{Knowing the Present}

So, where are we now? We may be beyond the halcyon days of pain management, the 1980 s and 1990s. In many ways, pain care represented a frontier specialty, and like the "old west," certain claims were made upon territories and practices. Indeed, some of the apparent advances were developed with a cowboy mentality. Most assuredly, the treatments were well intended and seemed like good ideas: spinal cord stimulators and intrathecal drug infusions were deemed major advances; epidural steroid injections and vertebroplasty became popular, despite minimal evidence for effectiveness, other than short-term pain relief (20); seemingly limitless protocols for opioid use in chronic nonmalignant pain became the norm (21). Today, however, newfound knowledge compels us to retreat from naïve élan, as the potential harm of such treatments becomes apparent (22).

What can the pain physician now offer the patient? Most state-of-the-art technical treatments for pain are still somewhat contentious (if not unproven), and long-term effects of many of the more innovative technological approaches remain as yet unknown. Some argue that injections provide unclear benefit and a defined risk of injury (23). This leaves the physician with a limited armamentarium of valid treatment options. Pharmaceuticals can be effective, but have proven problematic (24). NSAIDs may cause adverse gastrointestinal, cardiovascular, and CNS effects [25], and opioids can lead to tolerance and dependence, if not frank addiction (26). Moreover, the prolonged and/or escalative use of opioids is wrought with litigious issues, and the clinical relationship can become frankly adversarial under such circumstances (27).

Giordano and Schatman have identified 3 primary

ethical problems that arise from these issues:

1) under-treatment of pain,

2) over-utilization of pharmacologic treatments and technologies, and

3) conflict between physician and patient (and physician and regulatory and payment authorities) (2-4).

Indeed, pain remains undertreated. When new treatment options are made available, they often are largely technological and expensive. Moreover, economic factors frequently restrain, if not preclude the direct provision of clinical care to the individual patient.

Technological interventions may obviate the need for dangerous, addictive drugs, and the relative popularity of new technological innovations to some extent reflects a growing consensus that pharmaceuticals are largely ineffective. That is not to say that technology denies or refutes the benefit of drugs. In fact, cutting-edge bioscience (e.g. geno- and nanotechnologies) offers great potential to produce more target-specific, selective, non-abusable and hence increasingly effective pharmacological agents (28). But the number of patients that must be treated to obtain a "successful" outcome of $30 \%$ pain reduction compared to placebo often exceeds 4 , at a cost of hundreds of dollars per month, per drug. Likewise, controlled release preparations of opioids are priced at similarly exorbitant rates. The average patient cannot afford such treatments.

New technologies and techniques may be free of the adverse effects of older pharmacologic therapies, but are not without risk themselves - in part because of their relative novelty, and the contingent nature of our understanding of the brain-mind, and the capacity of pain to affect the CNS. Moreover, as we have noted, even the best technique or technology is of little benefit if it is not accessible and affordable to those who need it. So, as it stands, the primary care physician - as well as the pain specialist - must generally rely upon those therapeutics that are subsidized by insurance plans, and that are not exorbitantly priced. These are largely pharmacologic, and incur the aforementioned risks for the physician and patient alike. The perceived high risks of legal sanctions and malpractice suits inherent to pain care are particularly threatening to primary care physicians, 
given that practice scenarios frequently preclude the time and effort necessary to diligently monitor pain patients. Thus, primary care physicians become reluctant to treat pain, and may refrain from treating pain patients in general. This has resulted in an increasing tendency to refer pain patients to pain specialists for management.

But herein lies another problem, as the profession of "pain management" is not specific to a particular discipline, and in this way, may be inchoate. The 'pain specialist' may be an anesthesiologist, neurologist, physiatrist, psychiatrist, allied health provider or even complementary/alternative medicine practitioner (e.g. chiropractor, acupuncturist). The cynic may opine that pain management is, in some respects, a faux specialty. It lacks homogeneity, and in this heterogeneous composition, may dispossess the uniform scientific rigor to justify its independent existence, relative to the breadth and/or depth of knowledge required of other specialties. In many respects, the "cobbling together" of pain medicine from parts of other disciplines may obviate its capacity to achieve independent clinical autonomy or life (and therefore a detractor might be tempted to label the specialty after Mary Shelley's Prometheus).

\section{Foretelling - or at least Proposing - The Future}

Given the deficiencies of the specialty of pain medicine, what in fact, does pain relief require? We have recently addressed this issue, claiming that:

"...what [pain] relief involves - for both an individual patient and to the overall paradigm of pain care - is somewhat more complicated, and reveals a larger, more multidimensional obligation. Each and all of the inherent domains of knowledge that are essential to medical practice (regardless of discipline) are engaged so as to allow a theoretical, applied, experiential and contextual understanding of pain (as object), and its expression and effects in the pain patient as the subject of moral responsibility. Often, the obvious goal of relieving pain may, in fact, not be wholly possible. Intractable pain is a reality of several conditions. However, the intractability of pain need not imply the impossibility of ongoing commitment to the best care possible (29)."

The question then is how to provide appropriate care for patients in pain? The current paradigm does not appear to be working. And, in any case, given the present means of funding medical care, physicians may experience drastic cuts that will threaten the way pain currently is treated in this country. However , this may not be an altogether bad thing. The crisis in pain care may lead to new treatment approaches. Given the strong growth of consumerism affecting the practice of medicine today, it appears unlikely that the specialty of pain medicine will disappear entirely.

Pain medicine may ultimately achieve independent specialty status, but the end result will appear different than what we see now. Competent pain management requires time and commitment to the patient, and a solid physician-patient relationship. Pain management may be considered a form of primary care medicine, in its best iteration. But this is not the current paradigm for pain management. The incentive model of reimbursement has forced physicians to work piecemeal; each pain patient becomes a billable procedure.

A unified approach to addressing the crisis in pain medicine has been proposed that attempts to reinstate the role and importance of the primary care physician (30). To some extent, this already is happening in palliative care (as championed by the specialties of family- and internal medicine), and we believe that it can take place in pain medicine as well. Either the pain management specialist must become a primary care physician, or the pain specialist must conjoin the primary care physician to become a part of the solution, rather than merely abdicating responsibility to the specialist (who is ill-equipped to properly, effectively and singularly treat the pain patient on a long-term basis).

In many ways, this approach is a plea to return to the basics of medical practice, "...consistent with, and adherent to the epistemic, anthropologic, and ethical domains of the core philosophy of medicine" (31). One could add that pain management specialists must be grounded in the fundamentals of primary care medicine, or if not formally trained in primary care, must ascribe to its tenets. Simply, we must learn to integrate the bio-psychosocial model into the paradigm of pain care.

Giordano and Schatman's proposed plan for reforming and integrating pain care:

"...supports the basic deontic structure of the profession; allows for a more complete articulation of clinical and ethical responsibilities within the scope of particular general, specialty, and sub-specialty prac- 
tices, and upholds the value of pain care as an interpersonal interaction that seeks to execute good acts and ends as specifically defined by the needs of the patient, and parameters of the clinical relationship (2-4)."

Can or will the proposed paradigm be adopted? The current crisis of confidence in medicine in general, and pain medicine in particular, ensures that change must occur. If nothing else, funding for pain care specialists will decline, or evaporate altogether. Of financial necessity, pain medicine may be subsumed back into primary care. Perhaps, pain specialists are up to the challenge. Currently, there is an ongoing tension among the different disciplines classified under the rubric of pain management about which group will achieve superiority and assume the mantle of authority. Unfortunately, the current argument is not primarily about what is best for the patient, but more about shareholder stakes in the medical market.

We hope that wiser members of the field will prevail in the end. Some practitioners of pain medicine recognize the error of conflict, and appreciate the damage it will do to the cause and articulation of pain care as a profession. Some recognize that pain medicine, whether pharmacologically-based, or focused on interventional techniques, is actually a part of a (larger, more inclusive) palliative care paradigm. Palliative care differs from pain medicine in that it has not jettisoned patient centeredness in exchange for technology. Indeed, the patient remains the focus of palliative care, and the primary goal is symptom relief, irrespective of whether accomplished by high- or lowtech means.

A key question that remains is if the philosophy expounded here will survive and can inform and ultimately become policy. Although pain medicine - prima facie - seems to serve a public good, pain control (in and of itself) is not a central tenet of organized medicine. Despite lobbying by proponents of pain medicine to the contrary, patients do not have a right to pain relief (32). If pain relief is not a right, then funding for pain therapeutics will remain uncertain. Unless such interventions and practices appear to be affordable and economical, they may not be seen as viable, and thus will not be provided by generalists or specialists; pain relief must be "...a good deal." Certainly, at present, pain care appears neither affordable nor economical.

\section{Conclusion: Practicing These Acts}

We are fond of paraphrasing the contemporary virtue ethicist Alasdair Maclntyre's definition of practice as an exchange of goods between, and relevant to agents in a relationship (33). That said, we hold that the primary "good" of the clinical relationship in pain medicine is the "care" of pain, as this reflects its essential raison d'être. What course of action will be required to instantiate competent pain care in practice? As stated in the Hippocratic corpus, clinicians "... must be able to tell the antecedents, know the present, and foretell the future... (1)". We posit that pain physicians should return to their roots, with the explicit goal of helping the patient (and, at the very least, do no harm in both profession and practice). To this end, we advocate that clinicians play a greater role in guiding the course of medical practice. This entails working together with scientists to advance appropriate research and development of effective, affordable treatments, participating in guideline development, working to inform and formulate policy, and in this latter regard, partner with lawmakers to ensure continued patient access to proper pain care. And as befitting a classical but nonetheless perdurable definition of "care," the primary goal must always be an unwavering regard for the good of the patient.

\section{Acknowledgements}

Thanks to Holly Long and Sherry Loveless for editorial assistance in the preparation of this manuscript. 


\section{References}

1. Hippocrates. Epidemics Book I, XI-XIII; (WHS. Jones, trans.) Harvard University Press, Cambridge, MA, 2004, p. 165.

2. Giordano J. Ethics of, and in pain medicine: Constructs, content, and contexts of application Pain Physician 2008; 11: 1-5.

3. Giordano J, Schatman ME. A crisis in chronic pain care- An ethical analysis. Part one: Facts, issues, and problems. Pain Physician 2008; 11:54-62.

4. Giordano J, Schatman ME. A crisis in chronic pain care - An ethical analysis. Part two: Proposed structure and function of an ethics of pain medicine. Pain Physician 2008; 11:589-595.

5. Giordano J. Pain: Mind, Meaning and Medicine. PPM-Publishers' Press, Glen cove, PA, 2009.

6. Boswell MV, Giordano J. Evidence-based or evidence-biased: On the need to consider stakeholder values in research assessment. Pain Physician 2009; 12:912.

7. Eaton ML, Kennedy D. Innovation in Medical Technology: Ethical Issues and Challenges. Johns Hopkins University Press, Baltimore MD. 2007.

8. Giordano J. Technology in pain medicine: Research, practice, and the influence of the market. Prac Pain Management 2008; 8:56-59.

9. Giordano J. The neuroscience of pain, and the neuroethics of pain care. Neuroethics 2009; 2:1.

10. Giordano J. Techniques, technology and tekne: On the ethical use of guidelines in the practice of interventional pain medicine. Pain Physician 2007; 10:1-5.

11. Herzlinger R. Market-driven Health Care Perseus Books, New York 1998.

12. Giordano J. Cassandra's curse: Interventional pain management, policy and preserving meaning against a market mentality. Pain Physician 2006; 9:167170.

13. Pellegrino ED. Toward a reconstruction of medical morality: The primacy of the act of profession and the fact of illness. Medicine and Philosophy 1979; 4:3256.
14. Kaspar J, Boswell MV, Giordano J. Assessing chronic pain: Facilitating objective access to the subjectivity of pain. Prac Pain Management 2009; 9:55-59.

15. Walenstein SL. The VAS Relief Scale and other analgesic measures: The carryover effect in parallel and crossover studies. In:, Max MB, Portenoy RK, Laska EM (eds.) The Design of Analgesic Clinical Trials; Advances in Pain Research and Therapy, Vol 18. Raven Press, NY, 1991, p. 97-105.

16. Reiser S. Medicine and the Reign of Technology Cambridge University Press, Cambridge, 1981.

17. Giordano J. Complementarity, brainmind, and pain. Forsch. Komplementärmed 2008; 15:2-6.

18. Giordano J, Jonas WJ. Asclepius and Hygieia in dialectic: Philosophical, ethical and pragmatic bases of an integrative medicine. Integrative Medicine Insights 2007; 2:89-101

19. Giordano J, Benedikter R, Schatman ME. Toward pain care for a global community: From philosophy to economic considerations. In: Giordano J, Boswell MV (eds.) Pain Medicine: Philosophy, Ethics and Policy. Linton Atlantic Books, Oxon, UK, 2009, p.39-51.

20. Boswell MV, Trescot AM, Datta S, et al. Interventional techniques: evidencebased practice guidelines in the management of chronic spinal pain. Pain Physician 2007; 10:7-111.

21. Trescot A, Helm S, Hansen H, et al. Opioids in the management of chronic noncancer pain: an update of American Society of the Interventional Pain Physicians' (ASIPP) Guidelines. Pain Physician 2008; 11:S5-S62.

22. Cole BE. Opioid prescriptions and proscriptions: Twenty-one questions. In: Giordano J, Boswell MV (eds.) Pain Medicine: Philosophy, Ethics and Policy. Linton Atlantic Books, Oxon, UK, 2009, p. 177-199.

23. Huston C, Slipman C, Garvin C. Complications and side effects of cervical and lumbosacral selective nerve root injections. Arch Phys Med Rehabil 2005;
86:277-283

24. Wiffen P, Collins S, McQuay H, et a l. Anticonvulsant drugs for acute and chronic pain, Review. The Cochrane Database of Systematic Reviews, vol1. 2003.

25. Jones R, Rubin G, Berenbaum F, Scheiman J. Gastrointestinal and Cardiovascular Risks of Nonsteroidal Anti-inflammatory Drugs. Am J Med 2008; 121:464474 .

26. Ballantyne J, LaForge K. Opioid dependence and addiction during opioid treatment of chronic pain. Pain 2007; 1 29:235-255.

27. Giordano J. Pain, the patient and the physician: Philosophy and virtue ethics in pain medicine. In: Schatman ME (ed.) Ethical Issues in Chronic Pain Management. Informa, Boca Raton, 2007, p. 118.

28. Tate S. Molecular validation of pain targets. In: Bountra C, Munglani R, Schmidt WK (eds.) Pain: Current Understanding, Emerging Therapies and Novel Approaches to Drug Discovery. Marcel Dekker, NY, 2003, p.355-365.

29. Giordano J, Boswell MV. Prolegomenon: Engaging philosophy, ethics and policy in, and for pain medicine. In: Giordano J, Boswell MV (eds.) Pain Medicine: Philosophy, Ethics and Policy. Linton Atlantic Books, Oxon, UK, 2009, p. 1321.

30. Giordano J, LeRoy P, Uthaman U. On the role of primary care within a system of integrative multi-disciplinary pain management. Prac. Pain Management 2006; 6:66-69.

31. Giordano J. Moral agency in pain medicine: Philosophy, practice and virtue. Pain Physician 2006; 9:41-46.

32. Hall J, Boswell MV. Ethics, law and pain management as a patient right. In: Giordano J, Boswell MV (eds.) Pain Medicine: Philosophy, Ethics and Policy. Linton Atlantic Books, Oxon, UK, 2009, p. 125-137.

33. Maclntyre A. After Virtue. University of Notre Dame Press, Notre Dame, IN, 1984. 